As I stressed in the beginning of this address, it is, of course, far beyond my capacities to contribute in any direct way to the solution of the problems discussed among the experts at this congress. My only purpose has been to give an impression of a general epistemological attitude which we have been forced to adopt in a field as far from human passions as the analysis of simple physical experiments. I do not know, however, whether I have found the right words to convey this impression, and before I conclude, I may perhaps be allowed to relate an experience which once most vividly reminded me of my deficiencies in this respect. In order to explain to an audience that I did not use the word 'prejudice' to imply any condemnation of other cultures, but merely to characterize our necessarily prejudiced con- ceptual frame, I referred jokingly to the traditional prejudices which the Danes eherish with regard to their Swedish brothers on the other side of the beautiful Sound outside these windows, with whom we have fought through centuries even within the walls of this castle, and from contact with whom we have, through the ages, received so much fruitful inspiration. Now you will realize what a shock I got when, after my address, a member of the audience came up to me and said that he could not understand why I hated the Swedes. Obviously I must have expressed myself most confusingly on that occasion, and I am afraid that also to-day I have talked in a very obscure way. Still, I hope that I have not spoken so obscurely as to give rise to any such misunderstandings of the trend of my argument.

\title{
Modern Trends in Air Transport*
}

$\mathrm{M}^{\mathrm{os}}$ OST modern air transport is by means of the aeroplane, a body heavier than air, depending upon forward movement for sustentation. For purposes of this examination it can be considered to consist of four fundamentally different systems : (1) the lifting system, that is, the wings ; (2) the non-lifting system, principally the body, a structure with space for the load, a girder carrying the tail control units, and often the power plant; (3) the propulsive system comprising the engines and airscrews; (4) the control system, including all devices by which the pilot governs the movements of his aircraft. The trend in development of each of these is examined from the point of view of its approach towards air transport ideals of carrying capacity, speed, range, economy, comfort and safety.

The lift of a wing increases with its area, the square of the speed, and, in general, its angle of attack. Increase of lift therefore demands some combination of larger values of these. It must be remembered that carrying capacity is not gross lift; but rather the surplus of the total lift over that necessary to sustain the weight of the structure, engines, etc. Assuming wing structures carrying the same load per unit area, with the same geometry of structure and materials of construction, while the lift will increase as the square of the dimensions, the volume, and consequently the weight, of the wing will increase as

* Based on a lecture by Prof. W. F. Durand, emeritus professor of mechanical engineering in Stanford University, given at the recent meeting of the American Association for the Advancement of Science, Richmond, Virginia. the cube of these. This relationship, known as the square/cube law, implies that with weight increasing at a greater rate than lift, the carrying capacity of any wing system will ultimately be reduced to zero. The functioning of this law is being defeated by designers by the more efficient distribution of the materials in the structure, the use of specifically stronger (strength/weight) materials, and improved aerodynamic design allowing increased speed for the same power, and consequently extra lift from the same wing area. This is further helped by the fact that the power required is a factor of the wing area, and its weight is only increasing as the square of the linear dimensions of the machine. Increase in angle of attack, as a method of obtain. ing additional lift, results in an increase in drag of the wing at such a rate that the weight of the extra power plant necessary to overcome it soon cancels out its extra lift. As an example, early post-War commercial aeroplanes weighed from three to five thousand pounds with a wing loading of eight to twelve pounds per square foot, and there was evidence that the optimum size under the square/cube law was already approaching. A new Boeing flying boat, now building, will weigh $82,000 \mathrm{lb}$. with a carrying capacity of $10,000 \mathrm{lb}$., while some projected designs for trans-ocean services are of $200,000 \mathrm{lb}$. total weight and expect to carry a pay load of $25,000 \mathrm{lb}$., with wing loadings of $30-40 \mathrm{lb}$. per square foot.

The question of speeds is one of commercial requirements. They have risen from 50-80 miles per hour to 150-200 miles per hour normal cruising 
speeds, with much higher top speeds when necessary. The probable highest possible speed of flight that can be visualized at present is about 500 miles per hour, assuming a machine with its various characteristics combined in an optimum manner for this alone, a quite impractical proposition in many other respects. Excluding commercial stratosphere flight-as yet unproved-300 miles per hour appears to be about the practicable limit for commercial aircraft.

Range, the distance flown without alighting or refuelling, obviously depends upon an arbitrary balance between paying load and fuel carried. The theoretically maximum range, with no pay load, and neglecting the effect of weather conditions, assuming a machine designed specially for maximum performance in this respect, appears to be of the order of $8,000-9,000$ miles. The present record is about 7,000 miles, and it is not unfair to say that the reduction in this figure is largely due to adverse weather conditions and the limitations of the human element in the control of the machine. Economic considerations bring this figure down considerably ; the China Clipper flying boats on the Pacific service, making flights necessarily 2,000 miles in length, are not considered to be a paying proposition to-day. It is anticipated that the new 82,500 -lb. flying boat, already mentioned, will have an economic range of 2,400 miles at a cruising speed of 150 miles per hour. It is interesting to note that the cost of operating these long-range commercial flights is curiously stable at an average of 2 cents per passenger seat per mile.

These performances may also be modified by taking advantage of the reduced resistance of the more rarefied air at high altitudes. Here again record tlights on special machines $(52,937 \mathrm{ft}$.) have no commercial significance; but it appears that more economical flight should be possible in the sub-stratosphere between the altitudes of $20,000 \mathrm{ft}$. and $30,000 \mathrm{ft}$. Experimental flights at between $15,000 \mathrm{ft}$. and $20,000 \mathrm{ft}$. are already being arranged. The two essentials, that of supplying the engine with the necessary oxygen by supercharging it, and providing the air conditions required for the passengers' comfort by enclosing them in a pressuretight cabin, have already been accomplished. A Boeing No. 307 is being built for sub-stratosphere flight, with a range of 1,000 miles at 180 miles per hour, carrying a pay load of 9,200 lb.

Comfort for passengers is also an economic question, being principally one of the extra size of the body, with its additional drag and weight, the weight of furnishings of the cabin, the number of crew carried, provision of meals en route and more solid walls for sound- and weather-proofing. All of these are being met in a spirit of competition nowadays.
Safety, principally a matter of allowing for certain adverse weather conditions, can best be studied by considering those conditions in groups that affect an aeroplane differently. Structural breakages due to bad design are practically unknown, and failures of the power plant are being rapidly reduced to a negligible quantity. The Diesel type of engine with its simpler carburation, ignition, and less inflammable fuel, is the more attractive from this point of view, although its performance is inferior in some respects. Flying and navigational instruments are available for all needs, including blind flying and landing in fog, although the human element has to be considered in the limitation of the number of operations that any one person can carry out at the same time. Among more recent developments in this respect are an 'echo' altimeter giving the height of the machine above the ground in the immediate vicinity, a static suppressor that eliminates interference in radio communication, and an automatic radio direction finder working with a gyro-pilot. 'Stall' warning devices of various kinds, coupled with aerodynamic improvements in the control of a machine when flying slowly, have done much to reduce the hazards of taking-off and landing.

The autogyro - a rotating-wing aeroplane-and the helicopter-a flying propeller-are two developments that may have special applications because of some peculiarity that they possess; but their inferior performance in competition with the more conventional aeroplane would appear to limit their use for general air transport.

The position with regard to lighter-than-air craft is not so clear at the present time. Experience dictates that some inert gas, of which helium appears to be the only practicable one, must be used, for reducing fire danger. The restricted supply of this, limited to certain parts of the world, is likely to be a serious factor in the development of airships.

Structural failures in airships of the past have been serious, but lessons have been learned from their investigation, and it is claimed that airships could be built to-day with a structural margin of safety at least equal to a modern aeroplane. Airships are also immune from two possible dangers present in heavier-than-air craft: forced landing due to engine failure, and loss of control resulting in a spinning dive.

In conclusion, it is claimed that although practical flight, which came into being with the success of the Wright brothers in 1903, has presented the transport world with new problems by reason of the fact that it functions in an additional third dimension, they have not proved impossible of solution in both the technical and economic point of view. 